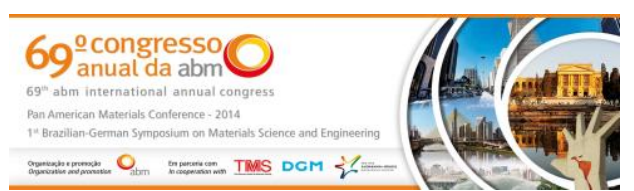

Tema: Diagramas de Fases e Transformações de fases

\title{
AVALIAÇÃO DA TÉCNICA DE EXTRAÇÃO DE FASES POR CORROSÃO SELETIVA DO AÇO UNS S31803 EM SOLUÇÃO 1M HCL A $60^{\circ} \mathrm{C}^{*}$
}

Fernanda Lourenço Fábia de Lima ${ }^{1}$ Rodrigo Magnabosco ${ }^{2}$

\section{Resumo}

O presente trabalho estuda a corrosão seletiva em chapas de aço inoxidável dúplex

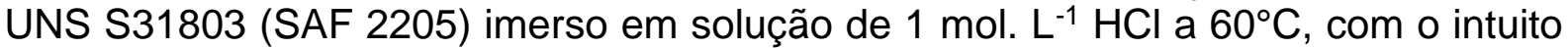
de extrair a fase ferrita, para se obter austenita e então criar padrões desta fase, gerando resultados mais confiáveis na sua quantificação, através das técnicas de difratometria de raios-X (DRX) e de espectroscopia de energia dispersiva (EDS). Este estudo foi realizado com 6 amostras, nas quais a temperatura de solubilização variou de $1.000^{\circ} \mathrm{C}$ até a $1.250^{\circ} \mathrm{C}$, a fim de se obter diferentes frações volumétricas de ferrita, podendo assim avaliar o comportamento de extração desta fase de cada amostra pela sua perda de massa em função do tempo de imersão. Os produtos de corrosão obtidos no ataque seletivo foram analisados pelas técnicas de DRX e EDS, onde se constatou o fenômeno de corrosão seletiva. Nas amostras solubilizadas foram feitas quantificações de fases pelas técnicas de DRX, estereologia quantitativa e ferritoscópio e verificou-se que todas apresentaram resultados distintos sendo que a que mais se aproximou da condição de equilíbrio calculada por Thermo-Calc foi a técnica de estereologia quantitativa.

Palavras-chave: Aço inoxidável dúplex; Corrosão seletiva; Caracterização de fases.

\section{EVALUATION OF THE SELECTIVE CORROSION FOR PHASE EXTRACTION ON $1 \mathrm{M}$ HCL SOLUTION AT $60^{\circ} \mathrm{C}$ IN UNS S31803}

\section{Abstract}

This work studies the selective corrosion in duplex stainless steel UNS S31803 (SAF 2205) sheets during immersion in a $1 \mathrm{~mol} . \mathrm{L}^{-1} \mathrm{HCl}$ solution at $60^{\circ} \mathrm{C}$, in order to extract the ferrite phase to obtain austenite, creating patterns of this phase to produce more reliable results of X-ray diffraction (XRD) and energy dispersive spectroscopy (EDS) analysis. This study was conducted in 6 samples, solution heat treated at temperatures from $1,000^{\circ} \mathrm{C}$ to $1,250^{\circ} \mathrm{C}$, in order to obtain different fractions of ferrite, evaluating the behavior of phase extraction of each sample by its weight loss as a function of immersion time. Corrosion products obtained after selective corrosion were analyzed by XRD and EDS techniques, where it was found the phenomenon of selective corrosion of ferrite. Solution-treated samples had their ferrite phase quantified by techniques of XRD, quantitative stereology and ferritoscope, and was verified that all samples presented different results, being the values closest to the equilibrium calculations by Thermo-Calc the ones obtained by quantitative stereology.

Keywords: Duplex stainless steel; Selective corrosion; Phase characterization.

1 Engenheira de Materiais, Centro Universitário da FEI, São Bernardo do Campo, SP, Brasil; fernandalima889@hotmail.com.

2 Prof., Dep. de Engenharia de Materiais, Centro Universitário da FEI, São Bernardo do Campo, SP, Brasil; rodrmagn@fei.edu.br.

* Contribuição técnica ao 69 Congresso Anual da ABM - Internacional e ao 14ํㅡㄹ ENEMET - Encontro Nacional de Estudantes de Engenharia Metalúrgica, de Materiais e de Minas, 21 a 25 de julho de 2014, São Paulo, SP, Brasil. 


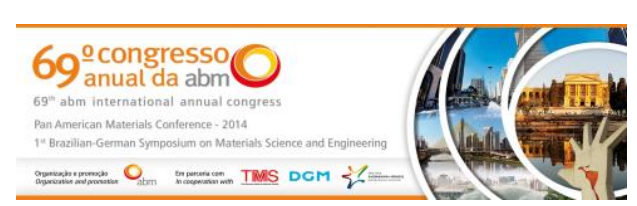

\section{INTRODUÇÃO}

Aços inoxidáveis dúplex (AID) são ligas ferro-cromo-níquel-molibdênio-nitrogênio, apresentando microestrutura contendo frações volumétricas aproximadamente iguais de ferrita (CCC) e austenita (CFC), obtidas por meio do tratamento térmico de solubilização. Na Figura 1 tem-se simulação de Thermo-Calc com a composição típica de um aço UNS S31803, quantificando as fases presentes em função da temperatura. Como características apresentam resistência à corrosão melhor ou igual aos melhores aços austeníticos empregados e limite de escoamento duas ou mais vezes superior, o que resulta na redução da espessura de parede de vasos de pressão e trocadores de calor, gerando menor peso, e consequentemente, maior economia de material e mão de obra na fabricação destes equipamentos [1].

Por conta destas propriedades, o aço inoxidável dúplex (AID) passou a ser empregado em indústrias químicas, petroquímicas, siderúrgicas, alimentícias, papel e celulose e de geração de energia [2].

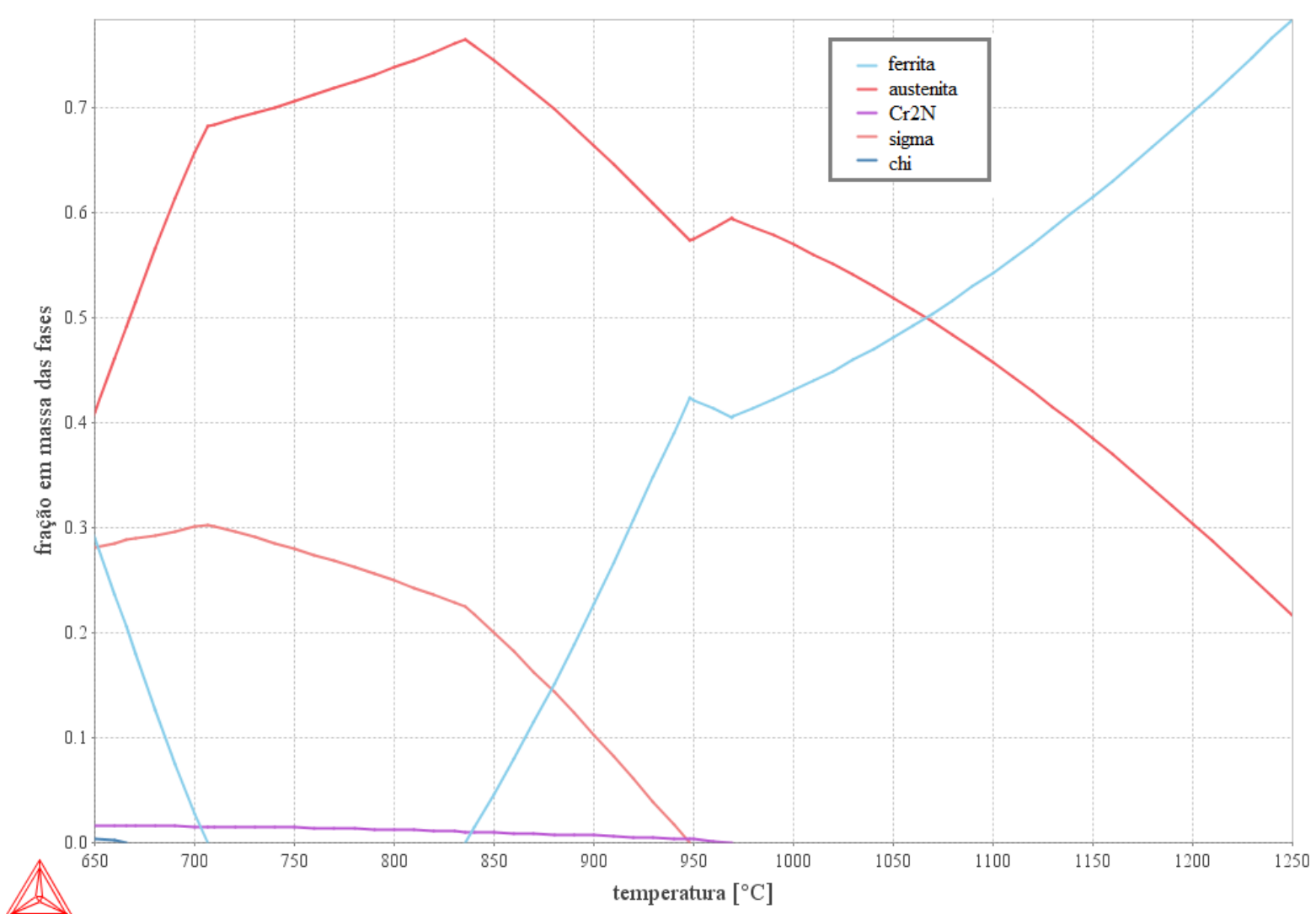

Figura 1. Simulação por Thermo-Calc ${ }^{\circledR}$, utilizando a base de dados TCFe7, das possíveis frações em massa das fases do aço em estudo.

No entanto, na indústria de papel e celulose, notou-se que no processo kraft há problemas de corrosão seletiva entre as fases constituintes do AID UNS S31803, quando simulada a limpeza do digestor com solução de ácido clorídrico $(\mathrm{HCl}) 1 \mathrm{M}$ a $60^{\circ} \mathrm{C}[3]$.

A corrosão seletiva é observada em ligas em que o mecanismo da corrosão implica na dissolução do componente mais ativo da liga (região anódica), enquanto que o metal mais nobre (material não atacado) atua como cátodo, dando origem a pilha galvânica [4].

* Contribuição técnica ao 69 Congresso Anual da ABM - Internacional e ao 14ํㅡㄹ ENEMET - Encontro Nacional de Estudantes de Engenharia Metalúrgica, de Materiais e de Minas, 21 a 25 de julho de 2014, São Paulo, SP, Brasil. 


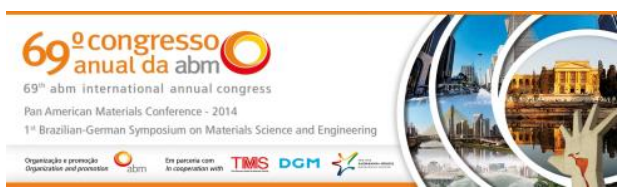

O fenômeno de corrosão seletiva foi observado no estudo de um aço UNS S31803 [5] num aço imerso na solução de $1 \mathrm{~mol}^{-1} \mathrm{~L}^{-1} \mathrm{HCl}$ a $60^{\circ} \mathrm{C}$. Notou-se que houve dissolução preferencial da fase ferrítica, provocando perda de massa em função do tempo de imersão na solução. $\mathrm{Na}$ análise do comportamento eletroquímico, feita pelos autores do referido trabalho, constatou-se a formação de dois picos de máxima densidade de corrente, em que um corresponderia ao potencial de dissolução da ferrita e o outro da austenita, característicos da dissolução seletiva das duas fases; no entanto, a ferrita é dissolvida em potenciais inferiores a austenita, confirmando o ataque preferencial a esta fase.

Quanto aos métodos de quantificação de fases para avaliar o efeito de corrosão seletiva, estudos anteriores [6,7] mostraram que técnicas de medição magnética, estereologia quantitativa, difração de raios- $X$ e simulação termodinâmica de equilíbrio apresentam distintos resultados de fração volumétrica da ferrita; e que a orientação cristalográfica preferencial impede a quantificação de fases, gerando resultados não confiáveis, sendo a estereologia quantitativa a técnica que mais se aproxima dos resultados teóricos esperados.

Considerando tais fatos, o presente projeto de pesquisa tem como objetivo promover a corrosão seletiva de ferrita de um aço UNS S31803 imerso em uma solução de $1 \mathrm{~mol}$. L-1 $\mathrm{HCl}$ a $60^{\circ} \mathrm{C}$, obtendo-se assim apenas a fase austenítica, permitindo a criação de padrões desta fase para análises de difratometria de raios-X (DRX) e análises de espectroscopia de energia dispersiva (EDS), podendo então gerar resultados mais confiáveis de quantificação.

\section{MATERIAL E MÉTODOS}

O aço UNS S31803 (SAF 2205) em estudo foi adquirido no formato de barras cilíndricas com $20 \mathrm{~mm}$ de diâmetro, laminadas a quente e tratadas termicamente na temperatura de $1100^{\circ} \mathrm{C}$ durante 30 minutos, sendo estas resfriadas em água. A composição química deste aço está demonstrada na tabela 1.

Tabela 1. Composição química (\% em massa) do aço em estudo.

\begin{tabular}{ccccccccccc}
\hline Material & $\mathrm{Cr}$ & $\mathrm{Ni}$ & $\mathrm{Mo}$ & $\mathrm{N}$ & $\mathrm{C}$ & $\mathrm{Mn}$ & $\mathrm{Si}$ & $\mathrm{P}$ & $\mathrm{S}$ & bal. \\
\hline SAF 2205 & 22,21 & 5,4 & 3,15 & 0,178 & 0,015 & 0,76 & 0,45 & 0,02 & 0,005 & $\mathrm{Fe}$ \\
\hline
\end{tabular}

Estas barras foram cortadas na seção transversal, obtendo-se 36 corpos de prova, de modo que estes ficaram no formato de discos com espessura de $5 \mathrm{~mm}$.

Todos os corpos de prova foram laminados a frio, no laminador de produtos planos, até atingirem uma espessura entre 0,5 a $0,7 \mathrm{~mm}$ de espessura, ou seja, sofreram reduções da ordem de 85 a 90\%, permitindo a mesma microestrutura de partida para a solubilização posterior.

Após a laminação, os 36 corpos de prova foram divididos em 6 amostras, e cada amostra foi submetida a tratamento térmico de solubilização, durante 6 horas nas temperaturas de $1000^{\circ} \mathrm{C}, 1050^{\circ} \mathrm{C}, 1100^{\circ} \mathrm{C}, 1200^{\circ} \mathrm{C}$ e $1250^{\circ} \mathrm{C}$. Em seguida, as amostras foram resfriadas rapidamente em água.

O objetivo da solubilização foi obter 6 diferentes frações volumétricas de austenita e ferrita para facilitar o processo de corrosão seletiva e total extração de uma das fases da amostra.

Depois da solubilização foram medidas a quantidade de ferrita presente em cada corpo de prova por meio do ferritoscópio, realizando-se medidas em cada amostra.

\footnotetext{
* Contribuição técnica ao $69^{\circ}$ Congresso Anual da ABM - Internacional e ao 14ํㅡㄹ ENEMET - Encontro Nacional de Estudantes de Engenharia Metalúrgica, de Materiais e de Minas, 21 a 25 de julho de 2014, São Paulo, SP, Brasil.
} 

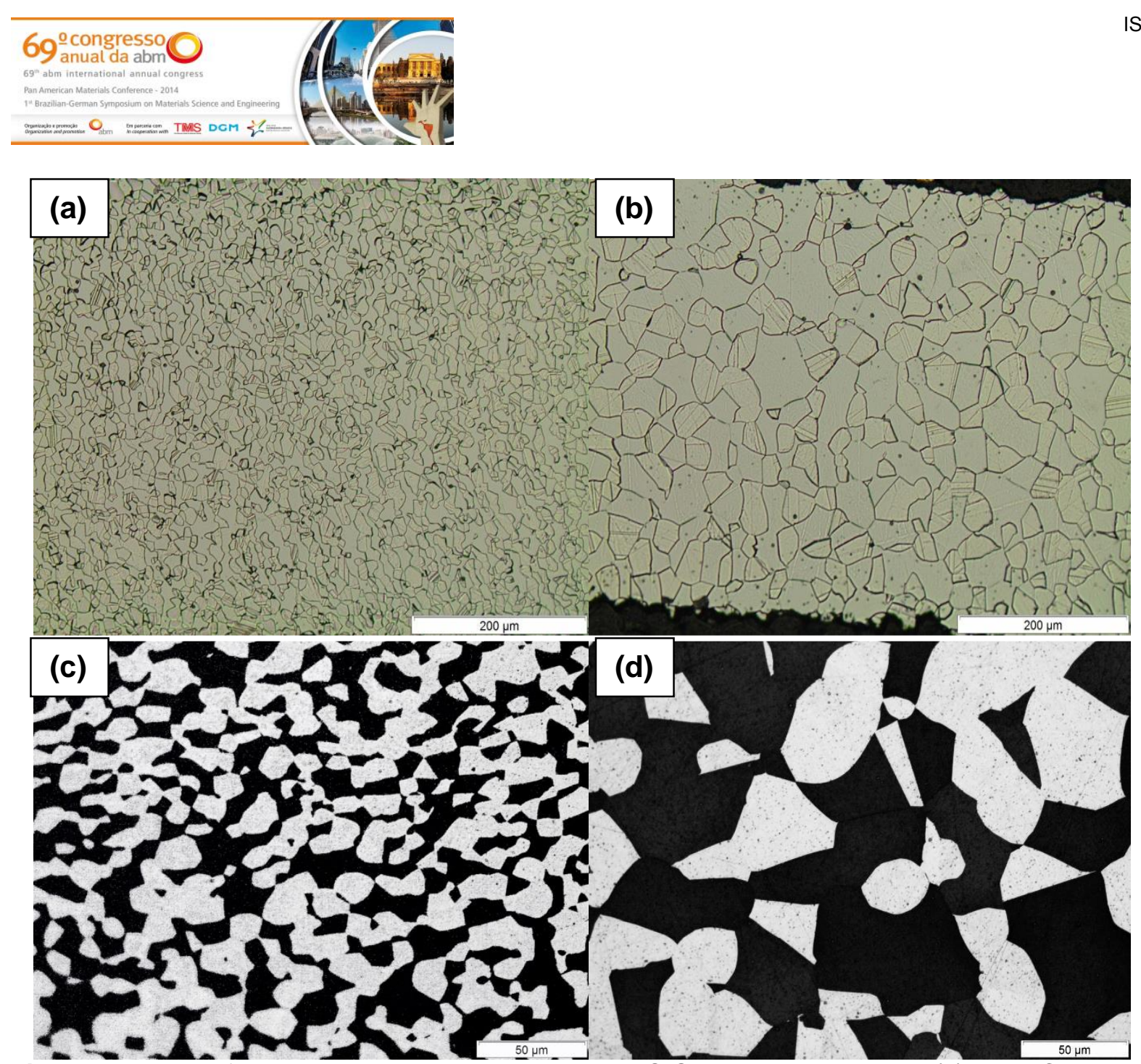

Figura 2. Micrografias da seção transversal do AID UNS S31803 solubilizado a (a) $1000^{\circ} \mathrm{C}$, ataque oxálico. (b) $1250^{\circ} \mathrm{C}$, ataque oxálico. (c) $1000^{\circ} \mathrm{C}$, ataque Behara. (d) $1250^{\circ} \mathrm{C}$, ataque Behara.

A figura 3 apresenta as técnicas utilizadas para medição volumétrica da fase ferrítica. Nota-se que a técnica mais próxima da condição de equilíbrio é a estereologia quantitativa, mas ainda assim nenhuma das técnicas apresentou tendência ao valor de equilíbrio calculado.

* Contribuição técnica ao 69ำ Congresso Anual da ABM - Internacional e ao 14ํㅡㄹ ENEMET - Encontro Nacional de Estudantes de Engenharia Metalúrgica, de Materiais e de Minas, 21 a 25 de julho de 2014, São Paulo, SP, Brasil. 


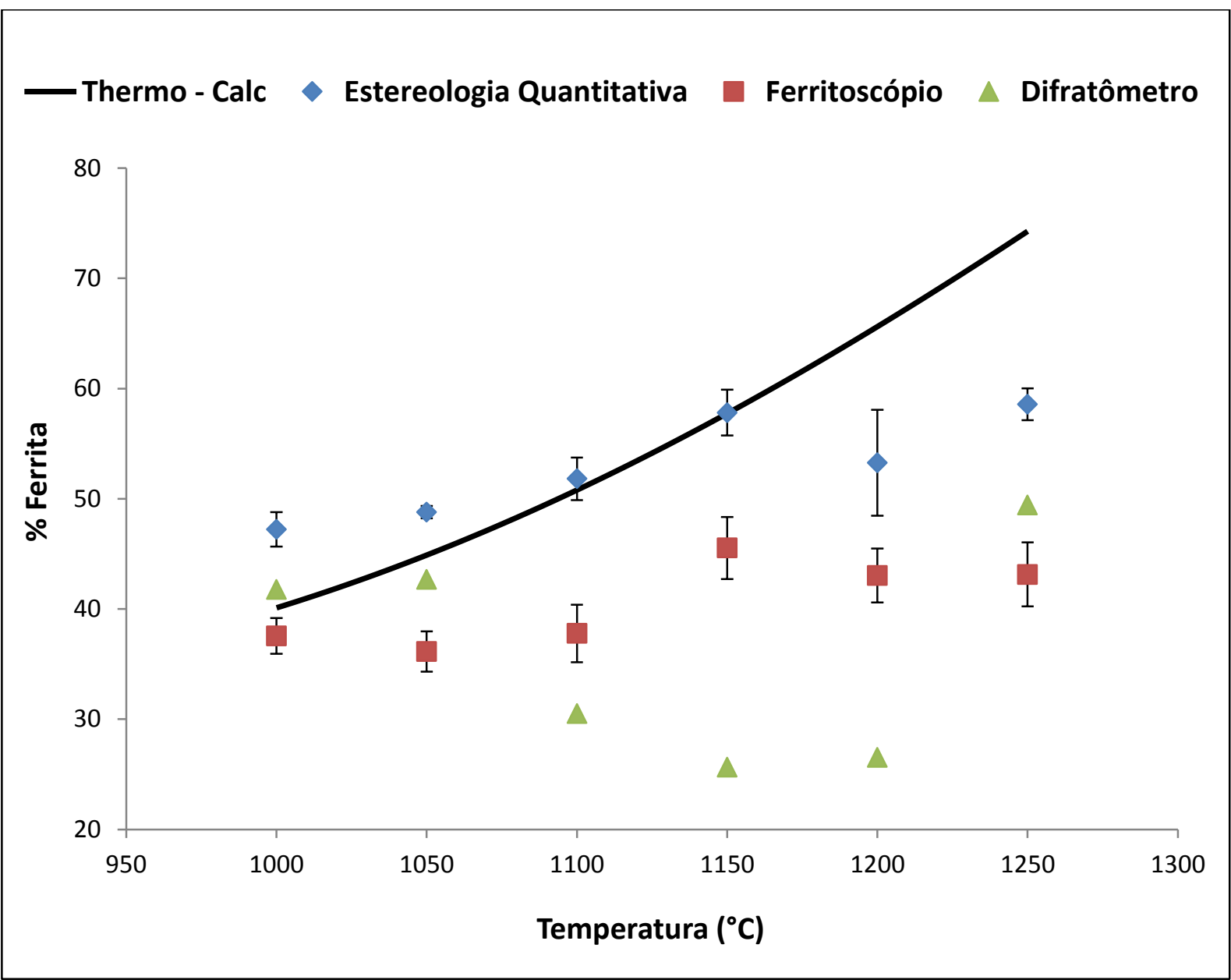

Figura 3. Gráfico do percentual de ferrita versus a temperatura de solubilização do aço AID UNS S31803.

A figura 4 apresenta o gráfico da perda de massa do $1^{\circ}$ corpo de prova de cada amostra em função do tempo de imersão na solução de $\mathrm{HCl} 1 \mathrm{M}$ a $60^{\circ} \mathrm{C}$. Nota-se que as amostras apresentam o mesmo comportamento de perda de massa, como mostram as equações que relacionam a perda de massa com o tempo de imersão, descritas na Tabela 2. 
(a)

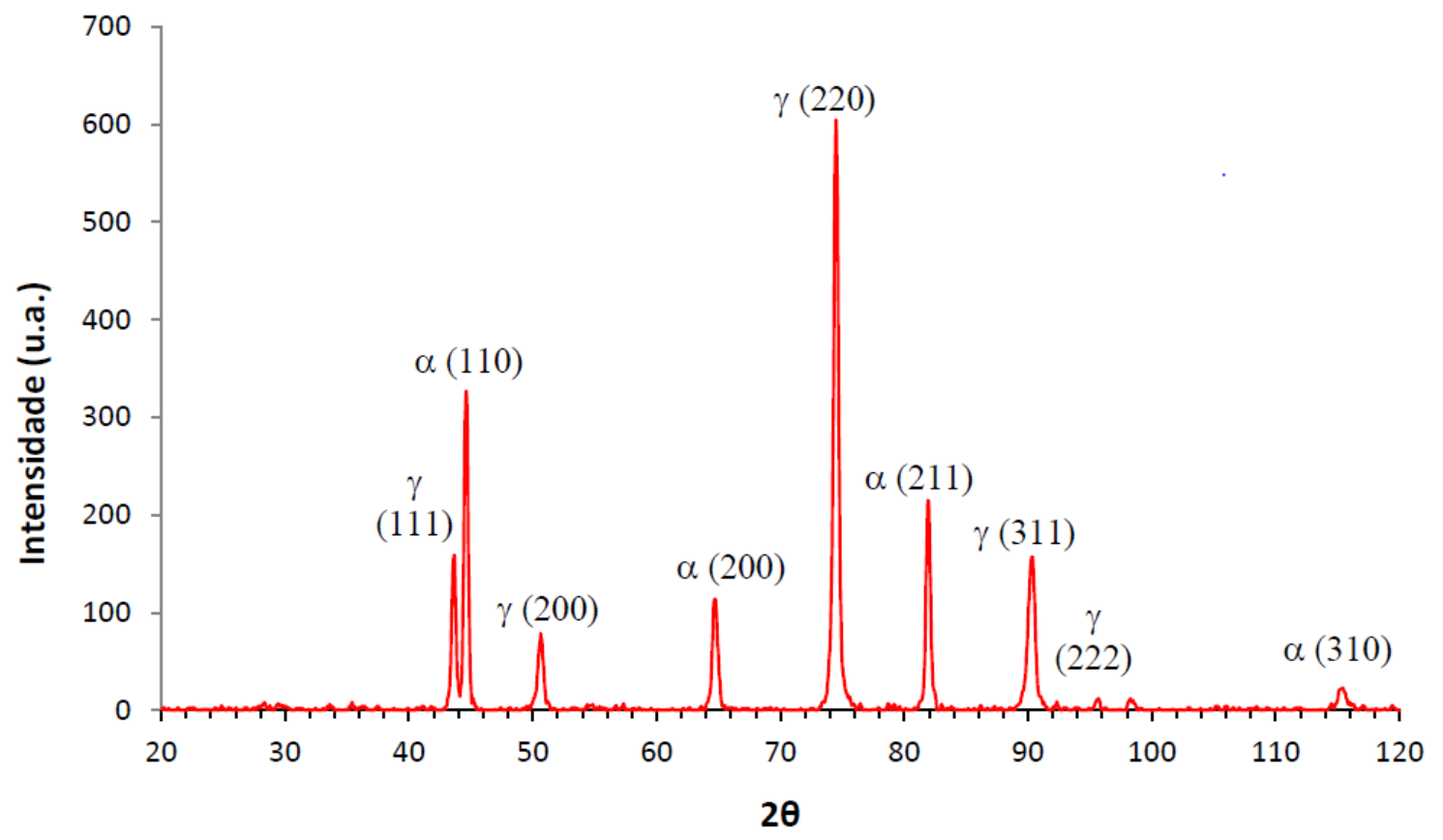

(b)

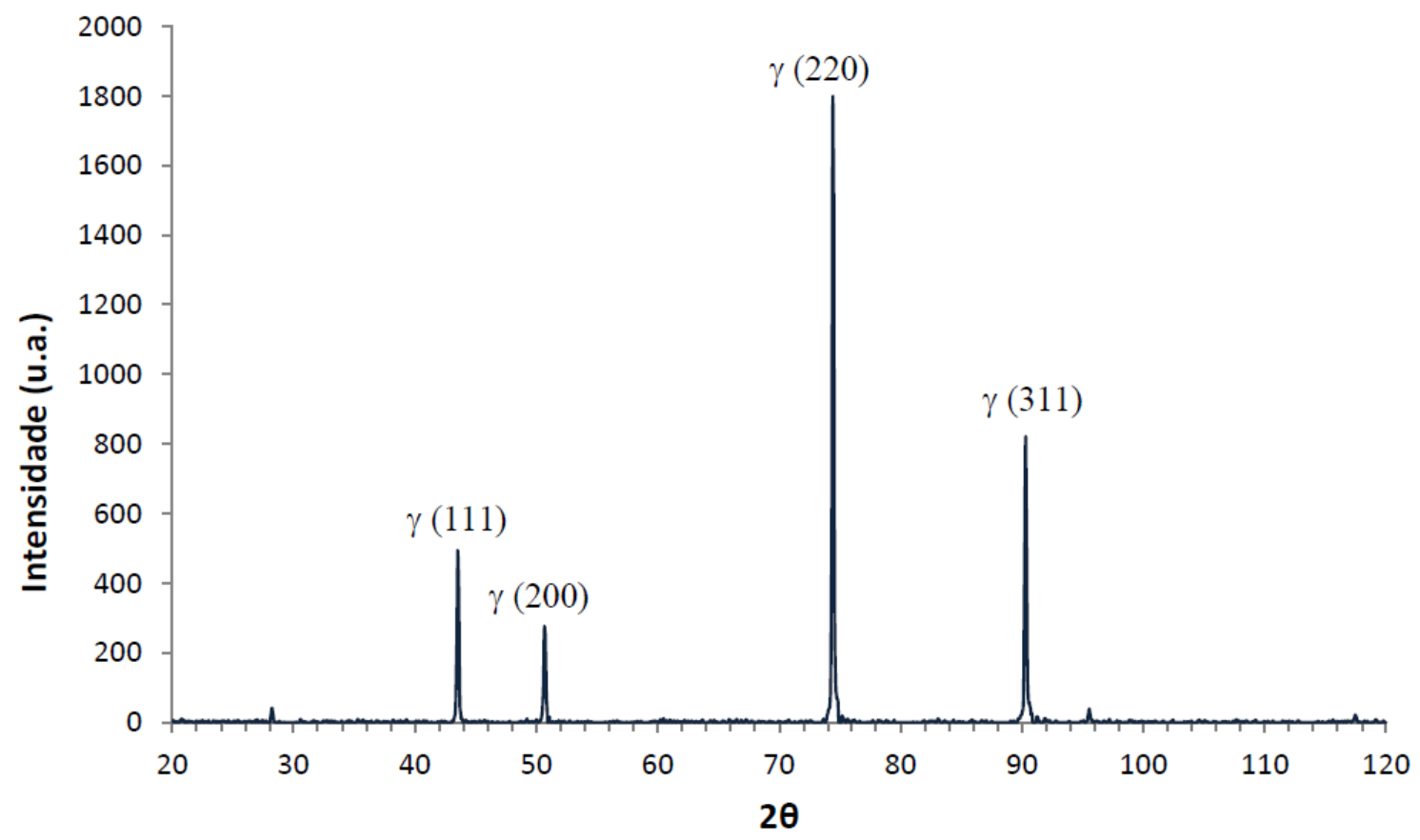

Figura 5. Espectro de difração de raios-X para o aço UNS $S 31803$ solubilizado a $1000^{\circ} \mathrm{C}$ por 6 horas. (a) Amostra original solubilizada. (b) Após ataque seletivo na solução de $\mathrm{HCl} 1 \mathrm{M}$ a $60^{\circ} \mathrm{C}$.

* Contribuição técnica ao 69 Congresso Anual da ABM - Internacional e ao 14ํㅡㄹ ENEMET - Encontro Nacional de Estudantes de Engenharia Metalúrgica, de Materiais e de Minas, 21 a 25 de julho de 2014, São Paulo, SP, Brasil. 


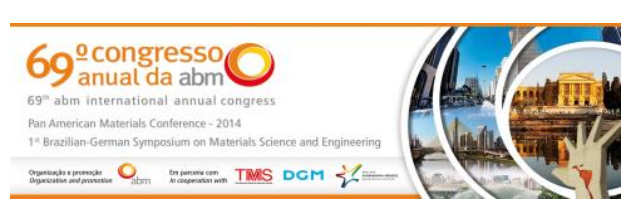

Tabela 3. Parâmetro de rede da fase ferrita $(\alpha)$ em função da temperatura de solubilização das amostras.

\begin{tabular}{cccccc}
\hline Temperatura $\left({ }^{\circ} \mathrm{C}\right)$ & 1000 & 1050 & 1100 & 1200 & 1250 \\
\hline$a(\AA)-\alpha$ & 2,88 & 2,88 & 2,88 & 2,88 & 2,87 \\
\hline Desvio padrão & 0,0035 & 0,0010 & 0,0003 & 0,0008 & 0,0016 \\
\hline
\end{tabular}

Tabela 4. Parâmetro de rede da fase austenita $(\gamma)$ em função da temperatura de solubilização das amostras.

\begin{tabular}{cccccc}
\hline Temperatura $\left({ }^{\circ} \mathrm{C}\right)$ & 1000 & 1050 & 1100 & 1200 & 1250 \\
\hline$a(\AA)-\gamma$ & 3,60 & 3,60 & 3,60 & 3,61 & 3,59 \\
\hline Desvio padrão & 0,0056 & 0,0010 & 0,0005 & 0,0026 & 0,0059 \\
\hline
\end{tabular}

Tabela 5. Parâmetro de rede da fase austenita $\left(\gamma^{*}\right)$ após corrosão seletiva, em função da temperatura de solubilização das amostras.

\begin{tabular}{cccccc}
\hline Temperatura $\left({ }^{\circ} \mathrm{C}\right)$ & 1000 & 1050 & 1100 & 1200 & 1250 \\
\hline$a(\AA)-\gamma^{*}$ & 3,60 & 3,60 & 3,60 & 3,59 & 3,60 \\
\hline Desvio padrão & 0,0023 & 0,0031 & 0,0009 & 0,0073 & 0,0034 \\
\hline
\end{tabular}

$\gamma^{*}=$ Austenita após ensaio de corrosão seletiva.

Pode-se notar que quase não houve alteração do parâmetro de rede a da fase austenita após corrosão seletiva, ou seja, não houve melhora no resultado de caracterização da estrutura cristalina desta fase.

A figura 6 apresenta as micrografias dos produtos de corrosão, obtidas no MEV. Nota-se, que embora o ataque preferencial seja da fase ferrita, a austenita também sofreu corrosão.

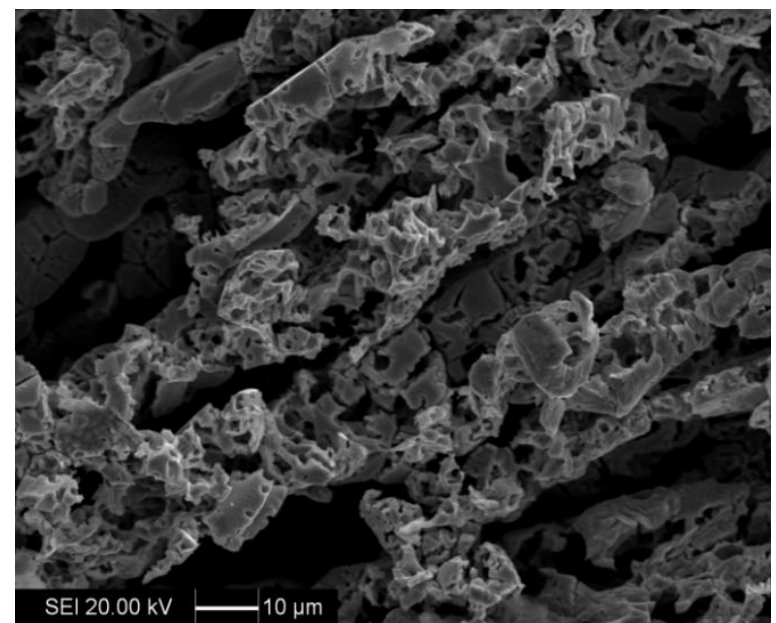

Figura 6. Micrografia obtidas no MEV da amostra solubilizada a $1000^{\circ} \mathrm{C}$, após corrosão seletiva.

A figura 7 apresenta o espectro da amostra solubilizada a $1000^{\circ} \mathrm{C}$ após ataque seletivo (produto de corrosão) e a tabela 6 apresenta a sua composição química, obtida pela técnica de EDS. Nota-se que os teores dos elementos químicos presentes no produto de corrosão correspondem ao esperado para a fase austenita, validando os resultados previamente apresentados de DRX.

\footnotetext{
* Contribuição técnica ao $69^{\circ}$ Congresso Anual da ABM - Internacional e ao 14ํㅡㄹ ENEMET - Encontro Nacional de Estudantes de Engenharia Metalúrgica, de Materiais e de Minas, 21 a 25 de julho de 2014, São Paulo, SP, Brasil.
} 


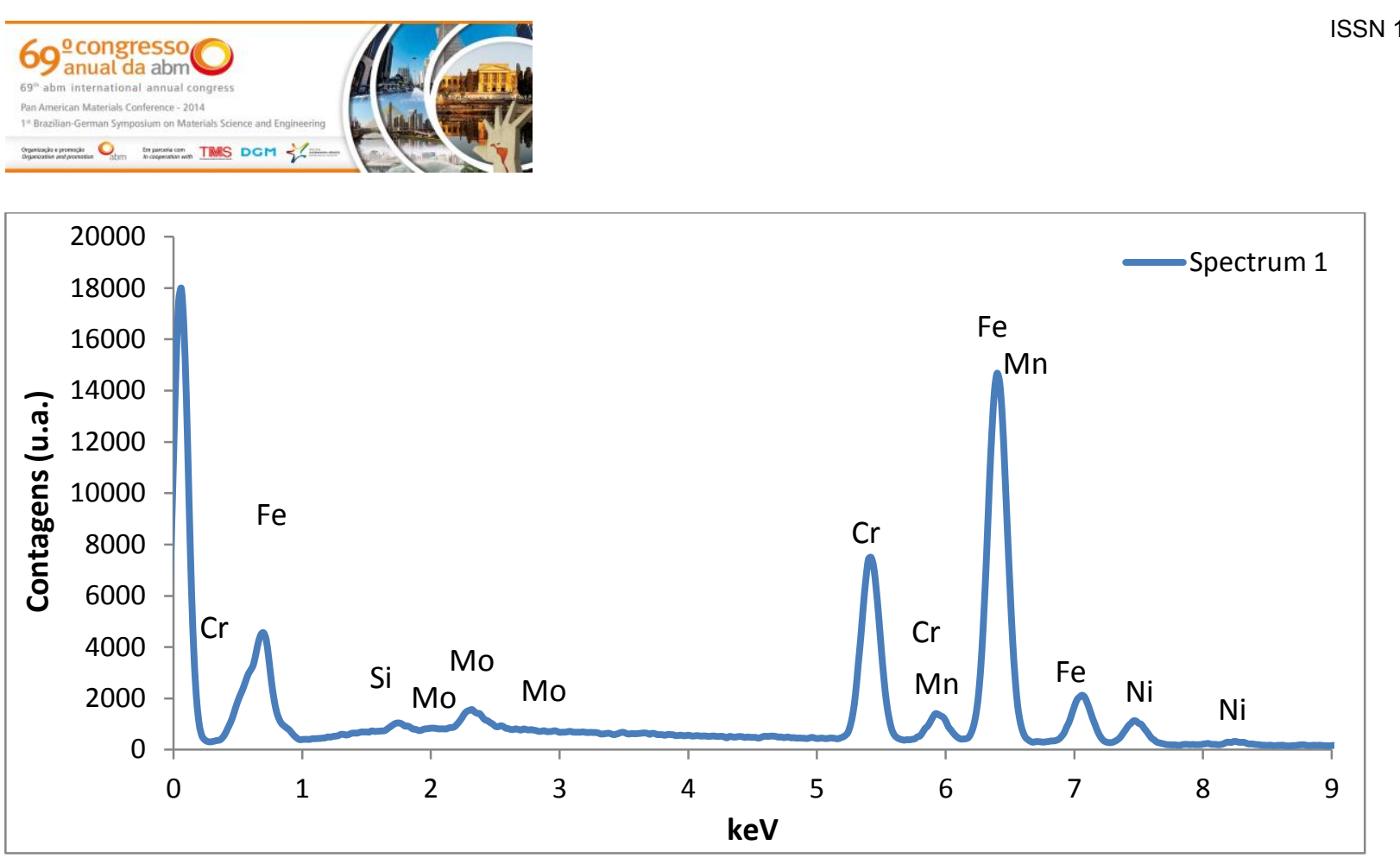

Figura 7. Espectro típico de EDS da amostra solubilizada a $1000^{\circ} \mathrm{C}$ após ataque seletivo.

Tabela 6. Composição química dos pontos analisados pelo espectro de raios-X, do aço AID SAF 2205 solubilizado a $1000^{\circ} \mathrm{C}$, após corrosão seletiva.

\begin{tabular}{c|c|c|c}
\hline Elementos & $\begin{array}{c}\text { Espectro 1 } \\
\text { (\% peso) }\end{array}$ & $\begin{array}{c}\text { Espectro 2 } \\
\text { (\% peso) }\end{array}$ & $\begin{array}{c}\text { Espectro 3 } \\
\text { (\% peso) }\end{array}$ \\
\hline $\mathrm{Si}$ & $0,65 \pm 0,07$ & $0,78 \pm 0,07$ & $0,38 \pm 0,06$ \\
\hline $\mathrm{Cr}$ & $21,56 \pm 0,14$ & $21,16 \pm 0,14$ & $21,69 \pm 0,15$ \\
\hline $\mathrm{Mn}$ & $0,64 \pm 0,11$ & $0,94 \pm 0,11$ & $0,87 \pm 0,11$ \\
\hline $\mathrm{Fe}$ & $67,47 \pm 0,22$ & $67,07 \pm 0,22$ & $67,99 \pm 0,22$ \\
\hline $\mathrm{Ni}$ & $6,66 \pm 0,15$ & $6,82 \pm 0,15$ & $6,46 \pm 0,15$ \\
\hline $\mathrm{Mo}$ & $3,03 \pm 0,16$ & $3,24 \pm 0,16$ & $2,6 \pm 0,15$ \\
\hline
\end{tabular}

\section{CONCLUSÕES}

Verificou-se ser possível a extração da fase ferrita do aço UNS S31803 para as amostras solubilizadas entre 1000 e $1250^{\circ} \mathrm{C}$.

No ensaio de corrosão seletiva, observou-se que todas as amostras apresentaram o mesmo comportamento em relação a perda de massa em função do tempo de imersão na solução de $\mathrm{HCl} 1 \mathrm{M}$ a $60^{\circ} \mathrm{C}$.

Nas micrografias da seção transversal das amostras solubilizadas, obtidas pelo microscópio óptico, observa-se que quanto maior a temperatura de solubilização, maior é o crescimento dos grãos.

As análises de DRX das amostras solubilizadas (sem corrosão) e dos produtos de corrosão mostrou o efeito de corrosão seletiva em todas as amostras, apresentando ataque preferencial a ferrita, uma vez que apenas a fase austenítica foi detectada nas amostras corroídas.

Nas micrografias dos produtos de corrosão, obtidas no MEV, notou-se que embora o ataque preferencial seja da ferrita, a austenita também sofreu corrosão. Contudo, não houve melhora significativa na quantificação desta fase, pois os picos de austenita detectados pelo DRX, antes e após corrosão seletiva, mostraram que a fase austenita manteve a mesma orientação cristalográfica.

\footnotetext{
* Contribuição técnica ao $69^{\circ}$ Congresso Anual da ABM - Internacional e ao 14ํㅡㄹ ENEMET - Encontro Nacional de Estudantes de Engenharia Metalúrgica, de Materiais e de Minas, 21 a 25 de julho de 2014, São Paulo, SP, Brasil.
} 


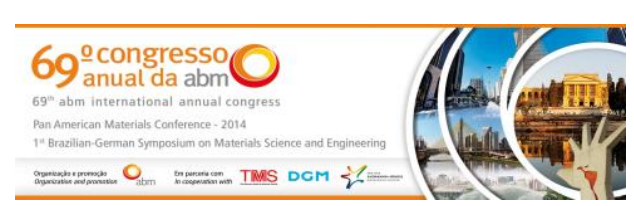

Já quanto as técnicas empregadas para quantificação de fases, todas apresentaram resultados distintos, sendo que a que mais se aproximou da condição de equilíbrio foi a técnica de estereologia quantitativa.

\section{REFERÊNCIAS}

1 Silva ALC, Mei RP. Aços e ligas especiais. 3. ed. São Paulo: Edgard Blücher; 2006.

2 Senatore M, Finzetto L, Perea E. Estudo comparativo entre os aços inoxidáveis dúplex e os inoxidáveis AISI 304L/316L. Rem: Rev. Esc. Minas. 2007;60(1). Disponível em: $<$ http://www.scielo.br/scielo.php?script=sci_arttext\&pid=S0370$44672007000100027 \&$ Ing $=$ en\&nrm $=$ iso $>$.

3 Santos DC. et al. Estudo comparativo da corrosão dos aços UNS S30400 (AISI 304), UNS S31603 (AISI 316L) e UNS S31803 (SAF 2205) no digestor do processo de polpa kraft [Monografia Graduação em Engenharia Química]. São Bernardo do Campo: FEl; 2007.

4 Wolynec S. Técnicas eletroquímicas em corrosão. $1^{\circ}$ ed. São Paulo: Editora da Universidade de São Paulo; 2003.

5 Santos DC, Magnabosco R. Estudo da corrosão seletiva em aço UNS S31803 (SAF 2205) em solução $1 \mathrm{M} \mathrm{HCl}$. In: IX Seminário Brasileiro de Aço Inoxidável, 2008, São Paulo. INOX 2008, 2008.

6 Magnabosco R, Santos DC, Melo E. Relation between microstruture and selective corrosion of duplex stainless steel submmited to heated chloridric acid. In: EUROCORR 2009, Nice. EUROCORR 2009. Paris: CEFRACOR, 2009. (mídia eletrônica).

7 Spomberg S. Uso da difratometria de raios-X na quantificação da ferrita e austenita em aços inoxidáveis dúplex [Monografia Iniciação Cientifíca]. São Bernardo do Campo: FEl; 2010.

* Contribuição técnica ao 69ำ Congresso Anual da ABM - Internacional e ao 14ํㅡㄹ ENEMET - Encontro Nacional de Estudantes de Engenharia Metalúrgica, de Materiais e de Minas, 21 a 25 de julho de 2014, São Paulo, SP, Brasil. 